\title{
Sugarcane bagasse for the removal of erythrosin B and methylene blue from aqueous waste
}

\author{
Pankaj Sharma · Harleen Kaur
}

Received: 26 June 2011/ Accepted: 5 October 2011/Published online: 21 October 2011

(C) The Author(s) 2011. This article is published with open access at Springerlink.com

\begin{abstract}
Present study explores the potentiality of locally available cellulose, hemicellulose and lignin-rich agricultural by-product sugarcane bagasse (SB) for the removal of erythrosin $\mathrm{B}(\mathrm{EB})$ and methylene blue (MB) from aqueous waste. The SB has been characterized by Fourier transform infrared and scanning electron microscopy analytical techniques. Batch experiments have been carried out to determine the influence of parameters like initial dye concentration, $\mathrm{pH}$ of the medium, contact time between the adsorbate and adsorbent, weight of adsorbent and system temperature on the removal of EB and MB. Optimum conditions for adsorption are found to be $\mathrm{pH}$ 9, temperature $308 \mathrm{~K}$ and an equilibration time of $1 \mathrm{~h}$. Under these conditions equilibrium isotherms have been analysed by Langmuir and Freundlich isotherm equations. Based on the Langmuir adsorption isotherm model, the predicted maximum monolayer adsorption capacities of SB for EB and $\mathrm{MB}$ are found to be $500 \mathrm{mg} \mathrm{g}^{-1}$ (at $328 \mathrm{~K}$ ) and $1,000 \mathrm{mg} \mathrm{g}^{-1}$ (at $308 \mathrm{~K}$ ), respectively. The separation factor reveals the favourable nature of the isotherm for the studied dyes-SB system. The thermodynamic study indicates that the adsorptions of dyes are spontaneous and endothermic process. High temperatures favour EB adsorption whereas optimum temperature for MB adsorption is $318 \mathrm{~K}$.
\end{abstract}

P. Sharma $(\bowtie) \cdot$ H. Kaur

Department of Chemistry, Lovely School of Sciences,

Lovely Professional University, Phagwara 144402, Punjab, India

e-mail: sharmapankaj47@yahoo.com

P. Sharma

Energy Materials Center, Korea Institute of Energy Research,

71-2 Jang-dong, Yusong-gu, Daejeon 305-343,

Republic of Korea
Keywords Erythrosin B - Methylene blue . Sugarcane bagasse $\cdot$ Adsorption $\cdot$ Isotherms

\section{Introduction}

Expansion of business activities and explosion of population coupled with industrial revolution results in pollution of water, air and soil. The discharge of pollutants from various industries poses threat to Earth's biodiversity. Among various types of environmental pollutions water pollution is of major concern and for its occurrence dye-based industries are the main cause and foremost. Dyes are released into the environment, entering into aquatic ecosystem, deteriorating the water quality and thereby affecting the flora and fauna. Globally, it is estimated that $10 \%$ of the total dyestuffs used or about $7 \times 10^{5}$ tons per annum are released into the environment. These dyestuffs cause aesthetic and real hazards to environment. The real hazards caused by these coloured and solid wastes in aqueous solution is considered as often toxic, carcinogenic, mutagenic or even explosive that might affect aquatic biota and also humans (Zahrim et al. 2011; Saha 2010; Han et al. 2008). These dyes get accumulated in living tissues throughout the food chain which has human at its top. Due to increasing use of dyes for various purposes, this danger seems to multiply. Thus, there is a need to control an emission of dyes into the environment.

In order to keep the ecosystem green, recently an increasing interest has been focused on the adsorption techniques (El-Sayed 2011; Aksu 2005). This technique is quite popular due to its simplicity as well as the availability of a wide range of adsorbents and it proved to be an effective and attractive process for the removal of nonbiodegradable pollutants (including dyes) from wastewater (Ali and Gupta 2007; Saad et al. 2010; da Silva et al. 2011). 
In the past decade, Gupta et al. (2000, 2004a, b, 2005, 2006a, b, 2007a, b, 2008a, b, 2009a, b, c, 2011) made some great efforts to give collective information through review articles and research papers/reports about the current available techniques and adsorbents, for the dye removal and decolourization of aqueous waste. Most commercial systems use activated carbon as adsorbent to remove dyes from water because of its significant adsorption capacity. Although activated carbon is a preferred adsorbent yet its widespread use is restricted due to its cost. In order to decrease the cost of treatment, some attempts have been made to find low-cost alternative adsorbents. Recently, numerous studies have been conducted to develop cheaper and effective adsorbents from a variety of starting materials. By selecting proper adsorbent, it is possible to make the adsorption process promising and economically viable for the removal of contaminants (Annadurai et al. 2002; Sivaraj et al. 2001). Therefore, it is preferable to use low-cost adsorbents such as an industrial waste, natural ores and agricultural by-products (Jain et al. 2003; Kumar and Sivanesan 2006; Han et al. 2006; Low et al. 2011; Sharma et al. 2010; Bhattacharya and Sharma 2004; Mall et al. 2005; Lakshmi et al. 2009; Mohanty et al. 2006). In our recently published review article (Sharma et al. 2011), we have compiled an extensive list of adsorbents obtained from different sources, and this review also reports the optimum processing parameters to get maximum dye removal from effluent water. In the same review article, a comparison between the adsorbent capacities of chemically modified, pre-treated, and untreated adsorbents has also been made.

The prime objective of the proposed work is to study the adsorption efficiency of SB for the removal of EB and MB from aqueous waste by adsorption treatment. Moreover, dynamical behaviour of adsorption has been measured by the effect of concentration, $\mathrm{pH}$, contact time, adsorbent dosage and system temperature. Equilibrium adsorption isotherms play an important role in the predictive modelling that is used for the analysis and design of adsorption systems. Therefore, adsorption equilibrium has also been modelled using the Langmuir and Freundlich adsorption isotherms. The dynamic steps involved in the adsorption have been evaluated at different concentrations and thermodynamic parameters such as Gibbs free energy change $\left(\Delta G^{\mathrm{o}}\right)$, enthalpy change $\left(\Delta H^{\mathrm{o}}\right)$ and entropy change $\left(\Delta S^{\mathrm{o}}\right)$ have also been calculated.

\section{Materials and methods}

Pre-treatment of SB

Sugarcane bagasse is collected from nearby sugar mill of Phagwara, Punjab, India and it is primarily washed with tap water at least four to five times. After that it is soaked into distilled water for $48 \mathrm{~h}$ and then dried for $24 \mathrm{~h}$ at $373 \mathrm{~K}$. The dried material is pulverized to convert it into fine powder and then used as adsorbent for the removal of EB and MB. Studies about surface functional groups and surface morphology of SB have been made by the most widely used diagnostic techniques, i.e. FT-IR and SEM, respectively (Ferrero 2007; Garg et al. 2004; Hameed 2009). FT-IR 8400 S spectrometer. The sample is prepared with $\mathrm{KBr}$ and pressed into pellets. A spectrum is collected in the mid-IR range from $400-4,000 \mathrm{~cm}^{-1}$ with a resolution of $1 \mathrm{~cm}^{-1}$. The morphology and particle size of SB specimen has been examined by SEM. For SEM, the sample is dispersed onto carbon tape and coated with gold using a sputter coater system to prevent charge accumulation on the sample. The SB particles are then observed on a JEOL JSM-5800 microscope operating in SEM mode at $20 \mathrm{kV}$.

\section{Dye solution}

For the present study, EB and MB have been supplied by $\mathrm{CDH}$ and Merck Specialities Pvt. Ltd., respectively. The dye stock solution of 1,000 ppm is prepared by dissolving $1 \mathrm{~g}$ of each dye in $1,000 \mathrm{~mL}$ of distilled water. The experimental solutions of desired concentrations are prepared by diluting the stock solution with distilled water. The characteristics and some properties of EB and MB are listed in Table 1.

\section{Sorption experiments}

The adsorption of EB and MB on SB in liquid-solid system has been studied using a standard batch technique. The adsorption experiments have been carried out in $250 \mathrm{~mL}$ conical flasks by mixing a pre-weighed amount of desired adsorbent and $25 \mathrm{~mL}$ of aqueous dye solution of fixed concentration. The flasks are then clamped in a horizontal shaker with an intensity of agitation $4 \mathrm{rps}$ to mix the reaction mixture for predetermined time interval at constant temperature. The agitation rate is same for all experiments. The parameters such as initial dye concentration, $\mathrm{pH}$ of the medium, time of contact, adsorbent dosage and system temperature are varied during different sets of batch experiments. After adsorption, the samples are filtered out using the Whatmann filter paper number- 42 and care has been taken to repeatedly centrifuge the solution at high speed to avoid any solid particles in the solution phase. The left out concentration in the supernatant solution after adsorption process has been analysed using a Systronics 2201 double beam UV-VIS spectrophotometer by recording the absorbance changes at a wavelength of maximum absorbance $(524 \mathrm{~nm}$ for $\mathrm{EB}$ and $668 \mathrm{~nm}$ for $\mathrm{MB})$. The amount of dye adsorbed on the adsorbent surface 
Table 1 Physico-chemical properties of dyes erythrosin B and methylene blue

\begin{tabular}{|c|c|c|}
\hline Dye & Erythrosin B & Methylene blue \\
\hline $\begin{array}{r}\text { Molecular } \\
\text { structure }\end{array}$ & $\mathrm{Na}$ & 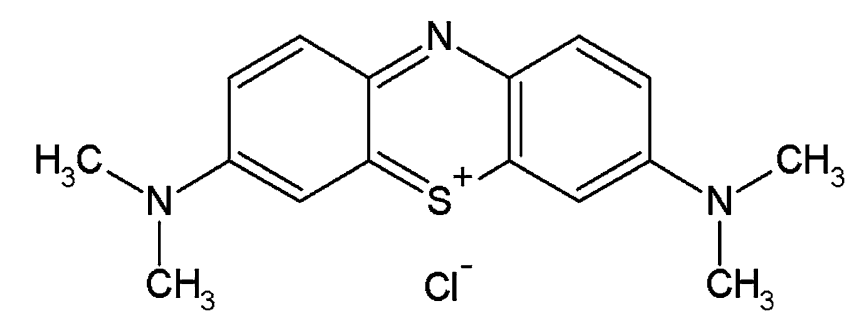 \\
\hline $\begin{array}{c}\text { Molecular } \\
\text { formula }\end{array}$ & $\mathrm{C}_{20} \mathrm{H}_{6} \mathrm{I}_{4} \mathrm{Na}_{2} \mathrm{O}_{5}$ & $\mathrm{C}_{16} \mathrm{H}_{18} \mathrm{~N}_{3} \mathrm{SCl}$ \\
\hline $\begin{array}{r}\text { IUPAC } \\
\text { name }\end{array}$ & $\begin{array}{l}\text { 2-(6-hydroxy-2,4,5,7-tetraiodo-3-oxo-xanthen-9-yl) } \\
\text { benzoic acid }\end{array}$ & 3,7-bis(dimethylamino)- phenothiazin-5-ium chloride \\
\hline Synonyms & $\begin{array}{l}\text { Erythrosine B; Acid red } 51 ; 2^{\prime}, 4^{\prime}, 5^{\prime}, 7^{\prime}-\text { Tetraiodo- } 3^{\prime}, 6^{\prime} \text { - } \\
\text { dihydroxy-spiro[3H-isobenzofuran-1,9'-xanthen]-3-one } \\
\text { disodium salt, Acid red } 51 \text { sodium salt, etc. }\end{array}$ & $\begin{array}{l}\text { 3,7-Bis(dimethylamino)5-phenothiazinium chloride, Aizen methylene } \\
\text { blue BH, Basic blue 9, Tetramethylthionine chloride, etc. }\end{array}$ \\
\hline $\begin{array}{l}\text { Molecular } \\
\text { weight }\end{array}$ & $879.86 \mathrm{~g}$ & $319.85 \mathrm{~g}$ \\
\hline $\begin{array}{l}\text { Solubility } \\
\text { in water }\end{array}$ & Soluble $(11 \%)$ & Soluble $(3.5 \%)$ \\
\hline $\begin{array}{l}\text { Absorption } \\
\text { maxima }\end{array}$ & $524 \mathrm{~nm}$ & $668 \mathrm{~nm}$ \\
\hline $\begin{array}{r}\text { Colour } \\
\text { index }\end{array}$ & 45,430 & 52,015 \\
\hline Appearance & Dark red powder & Dark green powder \\
\hline
\end{tabular}

has been calculated from the difference in the concentration of the solution phase before and after adsorption. All the experiments have been carried out in duplicate. The adsorption data is reported in terms of distribution coefficient $\left(K_{\mathrm{d}}\right)$ and adsorption percentage using the following equation:

$K_{\mathrm{d}}=\left[\frac{C_{\mathrm{o}}-C_{\mathrm{e}}}{C_{\mathrm{e}}}\right] \times\left[\frac{V}{W}\right]$

\%Adsorption $=\left[\left(C_{\mathrm{o}}-C_{\mathrm{e}}\right) / C_{\mathrm{o}}\right] \times 100$

where $C_{\mathrm{o}}$ and $C_{\mathrm{e}}$ are initial and equilibrium dye concentrations $\left(\mathrm{mg} \mathrm{L}^{-1}\right)$, respectively, $V$ is the volume of solution in $\mathrm{mL}$ and $W$ is the weight of adsorbent in $\mathrm{g}$.

\section{Thermodynamic parameters studies}

The $\Delta G^{\mathrm{o}}$ of the adsorption process is related to the equilibrium constant by the classic Van't Hoff equation:

$\Delta G^{\mathrm{o}}=-R T \ln K_{\mathrm{d}}$

According to thermodynamics, $\Delta G^{\mathrm{o}}$ is also related to the $\Delta S^{\mathrm{o}}$ and $\Delta H^{\mathrm{o}}$ at constant temperature by the following equation:
$\Delta G^{\mathrm{o}}=\Delta H^{\mathrm{o}}-T \Delta S^{\mathrm{o}}$

On combining Eqs. (3) and (4), we get

$\ln K_{\mathrm{d}}=-\Delta G^{\mathrm{o}} / R T=\left(\Delta S^{\mathrm{o}} / R\right)-\left(\Delta H^{\mathrm{o}} / R T\right)$

where the symbols have their respective meanings. $\Delta S^{\circ}$ and $\Delta H^{\mathrm{o}}$ can be recorded from the intercept and the slope, respectively, of linear Van't Hoff plot, i.e. $\ln K_{\mathrm{d}}$ versus $1 / T$.

\section{Adsorption isotherm}

Using a method of linear regression, the adsorption data have been fitted to Langmuir (Langmuir 1918) adsorption model to describe the adsorption processes between solidliquid interface.

Langmuir isotherm;

$C_{\mathrm{e}} / q_{\mathrm{e}}=1 /\left(K_{\mathrm{L}} q_{\mathrm{m}}\right)+C_{\mathrm{e}} / q_{\mathrm{m}}$

(Linear form)

$q_{\mathrm{e}}=\left(C_{\mathrm{o}}-C_{\mathrm{e}}\right) \times V / W$

where $q_{\mathrm{e}}$ is the amount of dye adsorbed per unit weight of adsorbent $\left(\mathrm{mg} \mathrm{g}^{-1}\right) . K_{\mathrm{L}}$ and $q_{\mathrm{m}}$ are the Langmuir coefficients representing the equilibrium constant for the adsorbate-adsorbent equilibrium and the monolayer capacity, 
respectively. A plot of $C_{\mathrm{e}} / q_{\mathrm{e}}$ versus $C_{\mathrm{e}}$ indicates a straight line of slope $1 / q_{\mathrm{m}}$ and an intercept of $1 / K_{\mathrm{L}} q_{\mathrm{m}}$. The value of $q_{\mathrm{m}}$ represents the practical limiting adsorption capacity or maximum value of monolayer adsorption.

Furthermore, the feasibility of the adsorption process is evaluated by the method suggested by Weber and Chakravorti (1974). One of the essential characteristics of Langmuir equation could be expressed by a dimensionless constant called equilibrium parameter or separation factor, $R_{\mathrm{L}}$ which can be calculated by the following equation (Hall et al. 1966):

$R_{\mathrm{L}}=1 /\left(1+K_{\mathrm{L}} C_{\mathrm{o}}\right)$

where $C_{\mathrm{o}}$ is the highest initial dye concentration $\left(\mathrm{mg} \mathrm{L}^{-1}\right)$.

The Freundlich isotherm is a special case for heterogeneous surface energy in which energy in the Langmuir equation varies as a function of surface coverage strictly due to variation of adsorption (Freundlich 1906). The linear form of Freundlich isotherm is given as:

$\log q_{\mathrm{e}}=\log K_{\mathrm{F}}+\frac{1}{n} \log C_{\mathrm{e}}$

where $K_{\mathrm{F}}$ and $n$ are Freundlich constants. The value of $K_{\mathrm{F}}$ can be taken as a relative indicator of adsorption capacity while $n$ shows the energy or intensity of adsorption.

\section{Results and discussion}

Fourier transform infrared spectroscopy analysis

The FT-IR spectrum of SB, presenting the plot of percentage transmission versus wave number, is given in Fig. 1. The FT-IR spectrum shows that sugarcane bagasse has functional groups of standard polymer $\alpha$-cellulose and coir pith-lignin. The FT-IR spectroscopic analysis indicates broad band observed at $3,424 \mathrm{~cm}^{-1}$ representing bonded -OH groups. The band observed at about $2,927 \mathrm{~cm}^{-1}$ could be

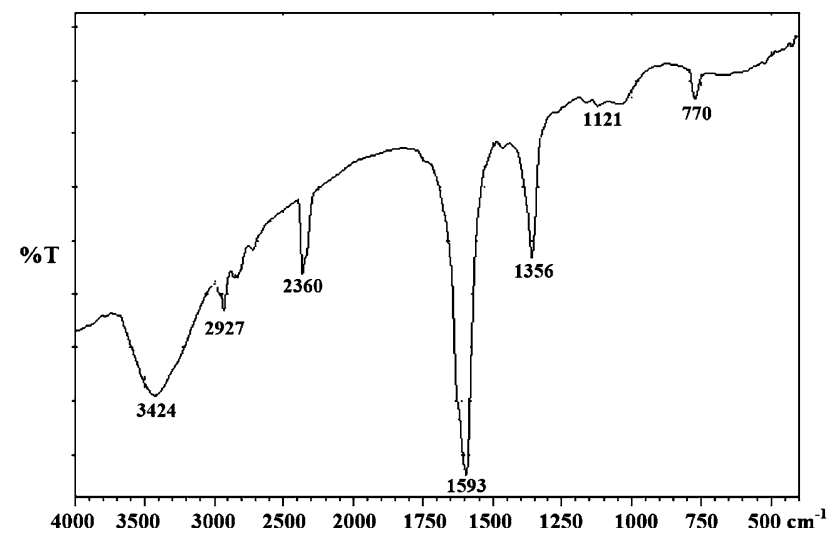

Fig. 1 FTIR spectra of SB assigned to the aliphatic $\mathrm{C}-\mathrm{H}$ group. The peaks described in the region of $1,600-1,590 \mathrm{~cm}^{-1}$ represent skeletal vibrations of benzene ring. The peaks observed at $1,420-1,300 \mathrm{~cm}^{-1}$ are attributed to $\mathrm{C}=\mathrm{C}-\mathrm{H}$ in plane bending indicating several bands in cellulose and xylose. Vibrational bands around wave number $1,356 \mathrm{~cm}^{-1}$ may be due to $-\mathrm{CH}_{2}$ wagging and twisting indicates several bonds in deoxysugars complex. The peak observed at $1,121 \mathrm{~cm}^{-1}$ represents $\mathrm{C}-\mathrm{O}-\mathrm{C}$ stretching as appears in polysaccharides.

\section{Scanning electron microscopic study}

The SEM images of typical SB sample at different magnifications have been taken to analyse the morphology of the material more clearly. Micrographs (Fig. 2) show that SB particles have fibrous character. These images also reveal that SB samples have compacted layer character in
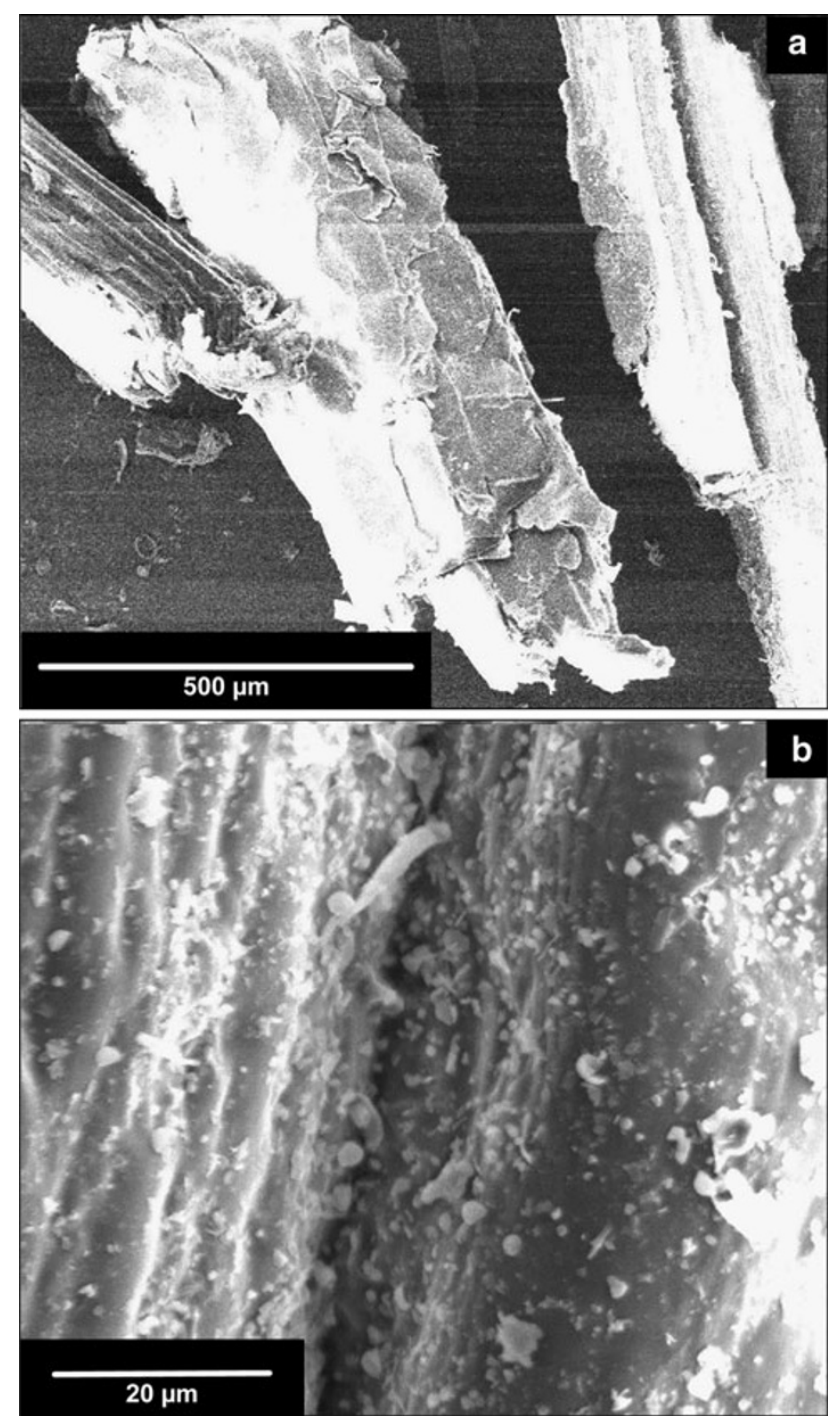

Fig. 2 SEM images of SB at two different magnifications 

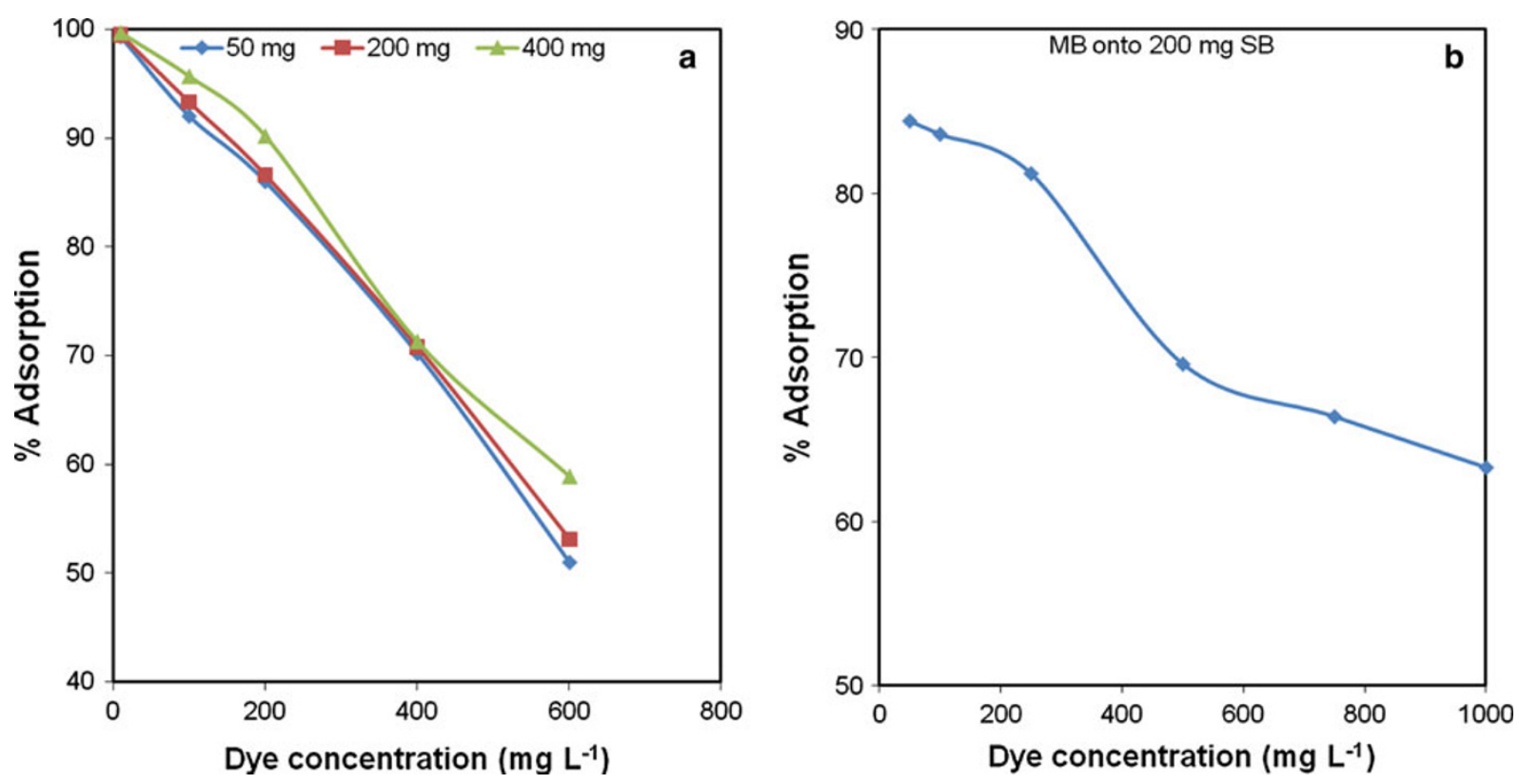

Fig. 3 Variation in percentage adsorption with dyes concentration: a EB on three different SB doses, b MB on $200 \mathrm{mg}$ of SB

which thin layers of cellulosic material are laying one on one. These fibres are of generally $\sim 1.0 \mathrm{~mm}$ in length and of $\sim 0.35 \mathrm{~mm}$ diameter. The second micrograph depicts that some very small particles of nearly $0.5-2.0 \mu \mathrm{m}$ in size adhere to the surface of large size fibres. These small grains may also take part in the adsorption process.

\section{Effect of initial concentration of dye on adsorption}

The effects of EB and MB dye concentrations on adsorption process have been studied at neutral $\mathrm{pH}$ and equilibration time of $1 \mathrm{~h}$. To study the effects of initial dye concentration, EB solution of concentration 10, 100, 200, 400 and $600 \mathrm{mg} \mathrm{L}^{-1}$ are used in conjunction with $\mathrm{SB}$ sample of 50, 200 and $400 \mathrm{mg}$. On the other hand, MB solution of concentration 100,500 and $1000 \mathrm{mg} \mathrm{L}^{-1}$ are used in conjunction with SB doses of 100, 200 and $400 \mathrm{mg}$. From Fig. 3 it has been found that the adsorption percentage decreases with increase in concentration of the adsorbate while the amount of dye removed at equilibrium increases with increase in dye concentration in both the cases. This is so because the initial dye concentration provides the driving force to overcome the resistance to mass transfer of dye (EB and $\mathrm{MB}$ ) between the aqueous and solid phase (Azhar et al. 2005).

\section{Effect of $\mathrm{pH}$}

The $\mathrm{pH}$ value of the solution is an important factor that must be considered during adsorption studies. The range of $\mathrm{pH}$ has been adjusted between $\mathrm{pH}$ 1-9. Digital $\mathrm{pH}$ meter (Model LT-10) has been used for the $\mathrm{pH}$ measurements.

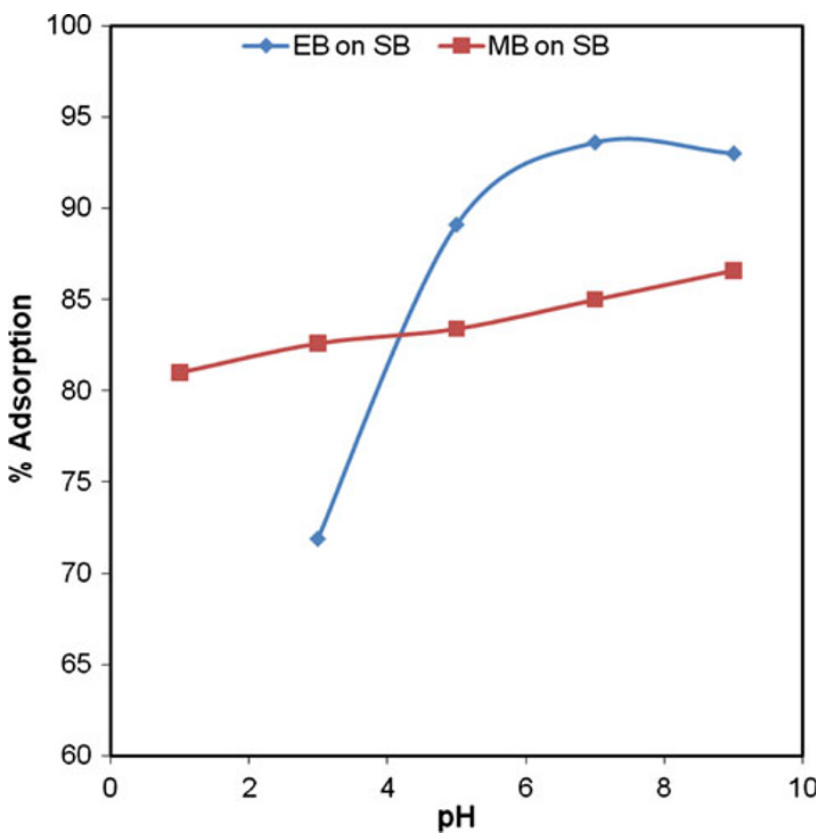

Fig. 4 Effect of initial $\mathrm{pH}$ of the medium on the adsorption of EB and $\mathrm{MB}$ on $\mathrm{SB}$

The initial $\mathrm{pH}$ of the working solutions has adjusted by addition of dilute $\mathrm{HCl}$ and $\mathrm{NaOH}$ solution (Analytical grade, $\mathrm{CDH}$ and S.D.fine Pvt. Ltd). The effect of $\mathrm{pH}$ on the adsorption of EB and MB by SB is shown in Fig. 4. It has been found that adsorption increases with increase in $\mathrm{pH}$. This may be due to the fact that at higher $\mathrm{pH}$ values the surface of adsorbent becomes negative which enhances the adsorption of positively charged $\mathrm{MB}$ cations through

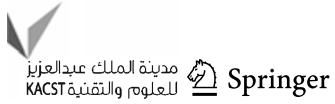


electrostatic force of attraction. Although EB is an anionic dye, it still shows maximum adsorption at high $\mathrm{pH}$ (7-9) which indicates that there is not much effect of hydroxide ion at these $\mathrm{pH}$ values. If we compare the \%adsorption of EB corresponding to $\mathrm{pH} 7$ and 9, then we find that amount of dye adsorbed on the adsorbent is nearly same (Zhang et al. 2011). This reveals that at neutral $\mathrm{pH}$, EB shows maximum adsorption.

\section{Effect of contact time}

Batch adsorption studies have also been conducted at different contact times (10, 30, 60, 90, 120, 150, and $180 \mathrm{~min})$ by taking initial concentration of dye $100 \mathrm{mg} \mathrm{L}^{-1}$ with $200 \mathrm{mg}$ adsorbent dose of SB in $25 \mathrm{~mL}$ dye solution of EB as well as $\mathrm{MB}$, at neutral $\mathrm{pH}$ and $308 \mathrm{~K}$ temperature. Effects of contact time on adsorption of EB and MB dyes onto SB are illustrated in Fig. 5. This data reveals that as the contact time increases, rate of adsorption first increases and then becomes almost constant. This is due to the aggregation of dye molecules with the increase in contact time, which makes it almost impossible to diffuse deeper into the adsorbent structure at higher energy sites. This aggregation negates the influence of contact time as the pores get filled up and start offering resistance to diffusion of aggregated dye molecules in the adsorbents (Mall et al. 2005). It has been seen that the equilibration time of $1 \mathrm{~h}$ is sufficient since maximum adsorption is attained during this period.

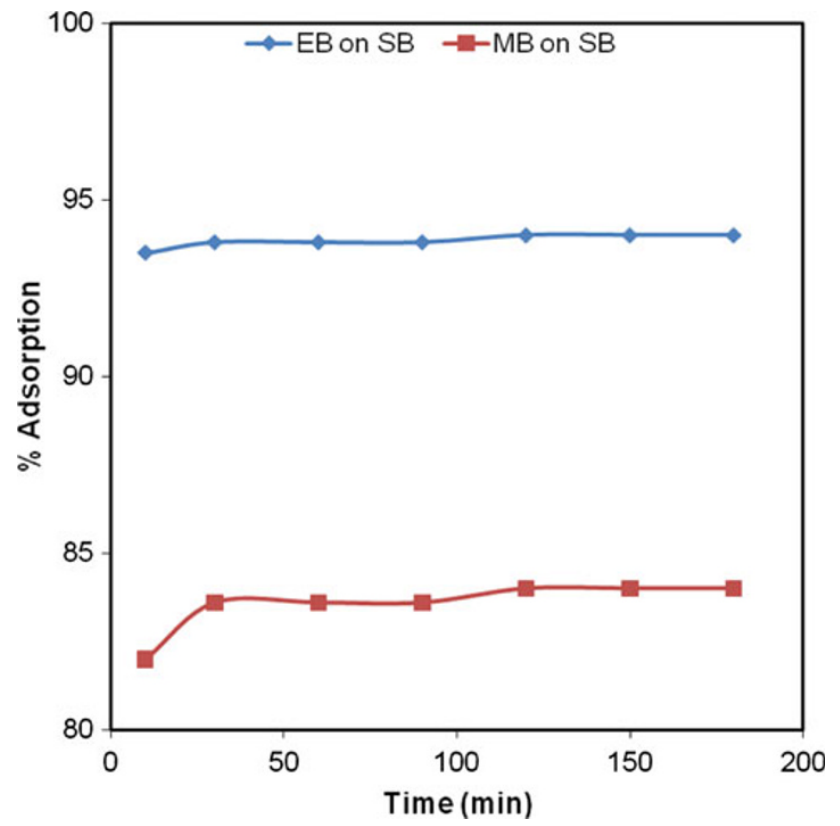

Fig. 5 Effect of contact time between the adsorbent and adsorbate on the percentage adsorption of $\mathrm{EB}$ and $\mathrm{MB}$ on $\mathrm{SB}$
Effect of adsorbent dosage

The adsorbent dose is also one of the important parameters to optimize an adsorption system. The effect of adsorbent dose on the adsorption of dyes has been investigated by employing different doses of SB varying from 50 to $1,500 \mathrm{mg}$. These adsorption experiments are performed at neutral $\mathrm{pH}, 308 \mathrm{~K}$, equilibration time $1 \mathrm{~h}$ and at different dye concentrations. Figure 6 demonstrates that the removal of dye increases with increase in adsorbent dosage. An increase in the adsorption with increase in adsorbent dosage can attribute to greater surface area and the availability of more adsorption surface sites (Sharma et al. 2010; Gupta et al. 2004b). It can be seen that for $10 \mathrm{mg} \mathrm{L}^{-1} \mathrm{~EB}$ solution, $50 \mathrm{mg}$ of $\mathrm{SB}$ in $25 \mathrm{~mL}$ is sufficient for the adsorption studies as it shows $100 \%$ adsorption but for higher concentration dye solutions, higher dosage of $\mathrm{SB}$ is required (Fig. 6a). While in case of MB removal, a high dosage of SB (Fig. 6b) is required even for low-concentrated dye solution.
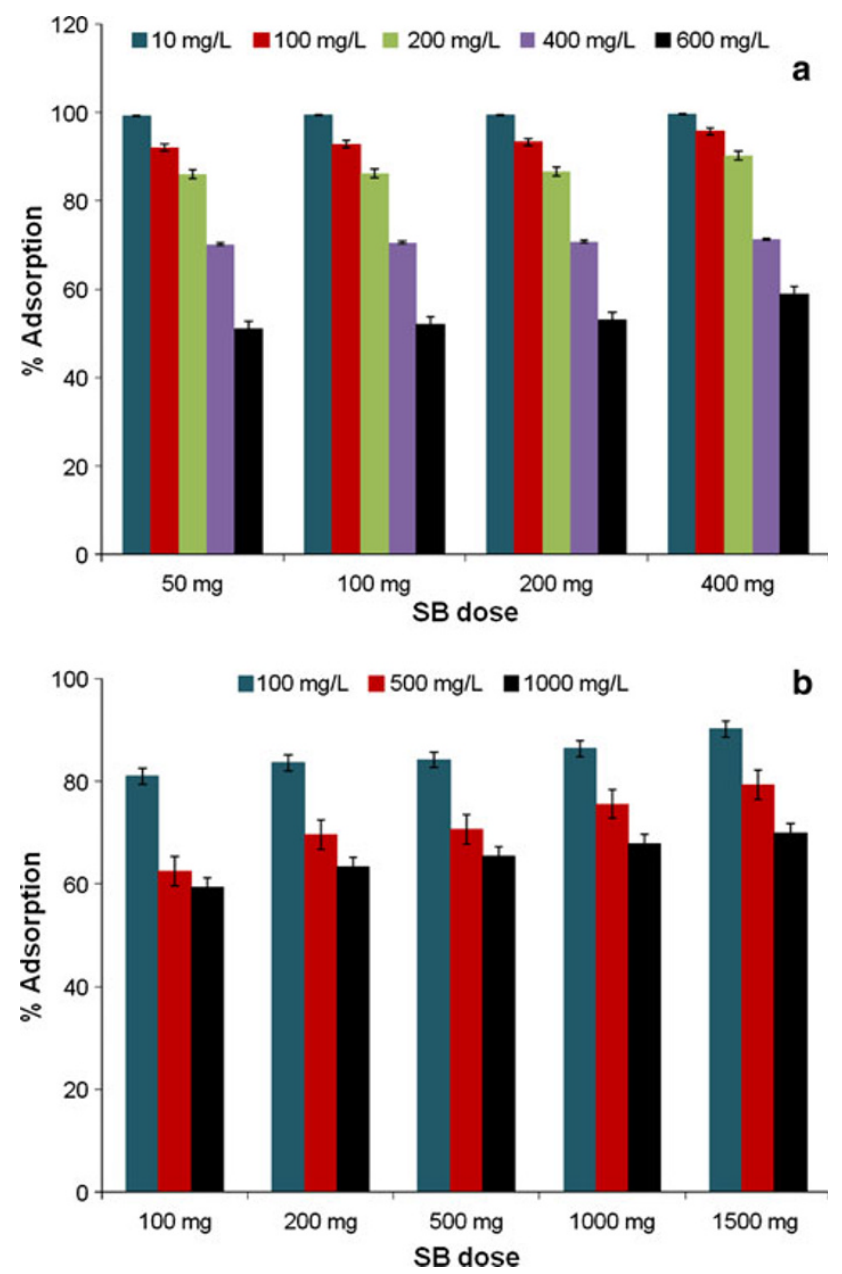

Fig. 6 Variation in percentage adsorption of: a EB on SB and $\mathbf{b} \mathrm{MB}$ on SB at three concentrations with change in adsorbent doses 


\section{Effect of temperature}

In order to optimize the system temperature for the maximum removal efficiency, experiments have been conducted at three different temperatures 308,318 and $328 \pm 0.1 \mathrm{~K}$ by varying dye concentration and keeping other parameters constant such as neutral $\mathrm{pH}$, equilibration time $1 \mathrm{~h}$, adsorbent dose of $200 \mathrm{mg}$. Experimental results concerning the effect of temperature on the adsorption of dyes at different initial dye concentration are demonstrated in Fig. 7. In case of EB adsorption on SB, the adsorption percentage increases when the temperature of solution is increased from 308 to $328 \mathrm{~K}$ which indicates that the process is endothermic in nature. Better adsorption at higher temperature may be either due to the acceleration of some originally slow adsorption steps or due to the retardation of the processes such as association of ions, aggregation of molecules, ion pairing and complex formation in the system because of thermal agitation. This can also be due to
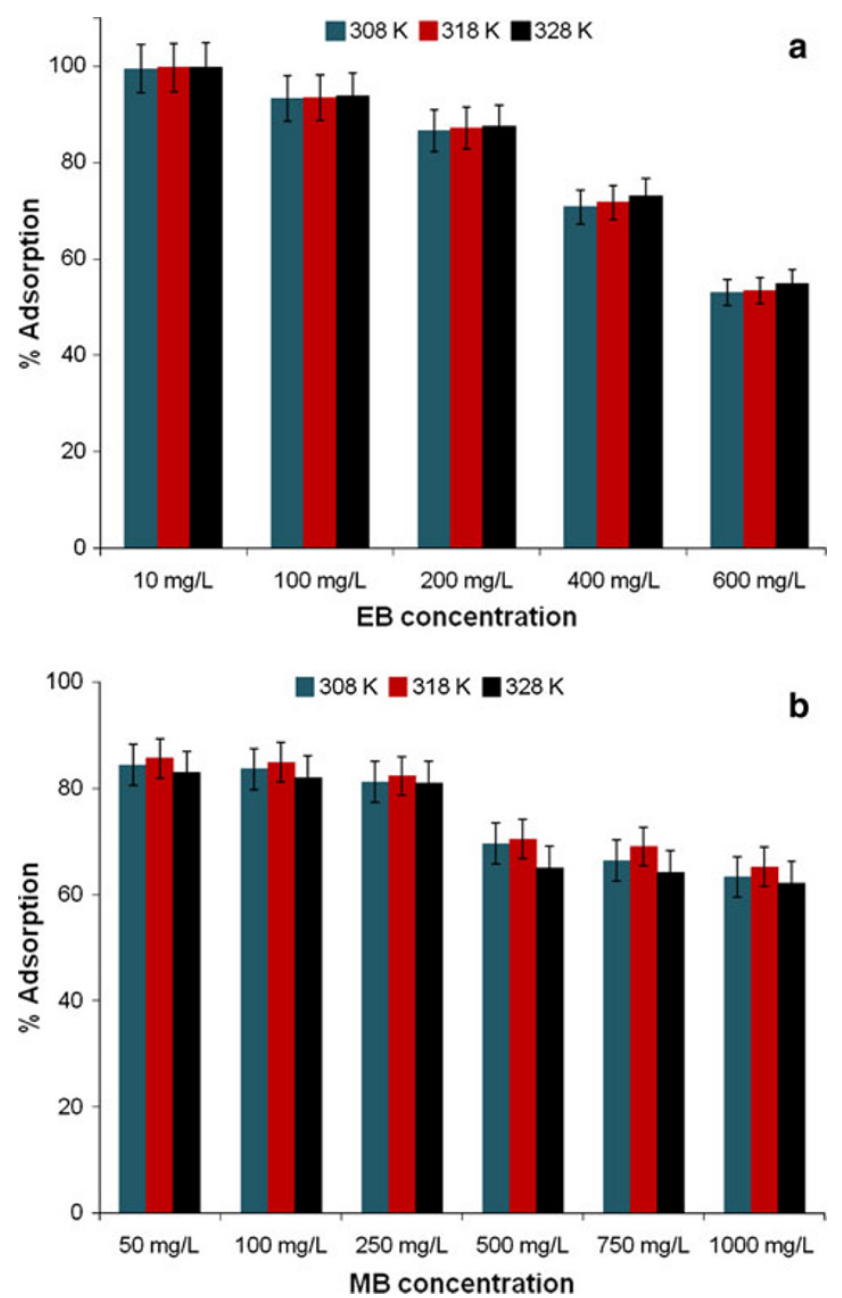

Fig. 7 Effect of temperature on percentage adsorption of: a EB on $\mathrm{SB}$ and $\mathbf{b} \mathrm{MB}$ on $\mathrm{SB}$ at different dye concentrations creation of new active sites on the adsorbent surface. Thus, an increase in temperature will reduce the electrostatic repulsion between the surface and the adsorbing species and this allow adsorption to occur more readily. This could also be due to enhanced mobility of dye molecules from solution to the sorbent surface (Sharma and Tomar 2011). Furthermore, increasing temperature may produce a swelling effect within the internal structure of SB enabling large dye to penetrate further. In case of MB, the adsorption percentage first increases when temperature rises from 308 to $318 \mathrm{~K}$ and then start decreasing with further increase in temperature indicating that the process is exothermic in nature. This decrease indicates that there are very weak binding forces between the dye molecule and adsorbent surface which may break at high temperature. This is because with increasing temperature the attractive forces between adsorbent surface and dye molecule are weakened and the adsorption decreases $(>318 \mathrm{~K})$. Increase in temperature may also cause the more pore expansion which may leads to leaching of MB molecules adsorbed on the SB (Khattri and Singh 2011).

\section{Thermodynamic parameters}

Thermodynamic parameters, i.e. free energy change $\left(\Delta G^{\circ}\right)$, enthalpy change $\left(\Delta H^{\circ}\right)$ and entropy change $\left(\Delta S^{\circ}\right)$, vary with the thermodynamic equilibrium constant $\left(K_{\mathrm{d}}\right)$ (Fig. 8) and have been calculated using standard equations (Eqs. 3 and 5) mentioned above. The values of thermodynamic parameters for EB on SB are reported in Table 2. The negative values of $\Delta G^{\circ}$ obtained in both the cases reveal that the adsorption of dye is thermodynamically feasible

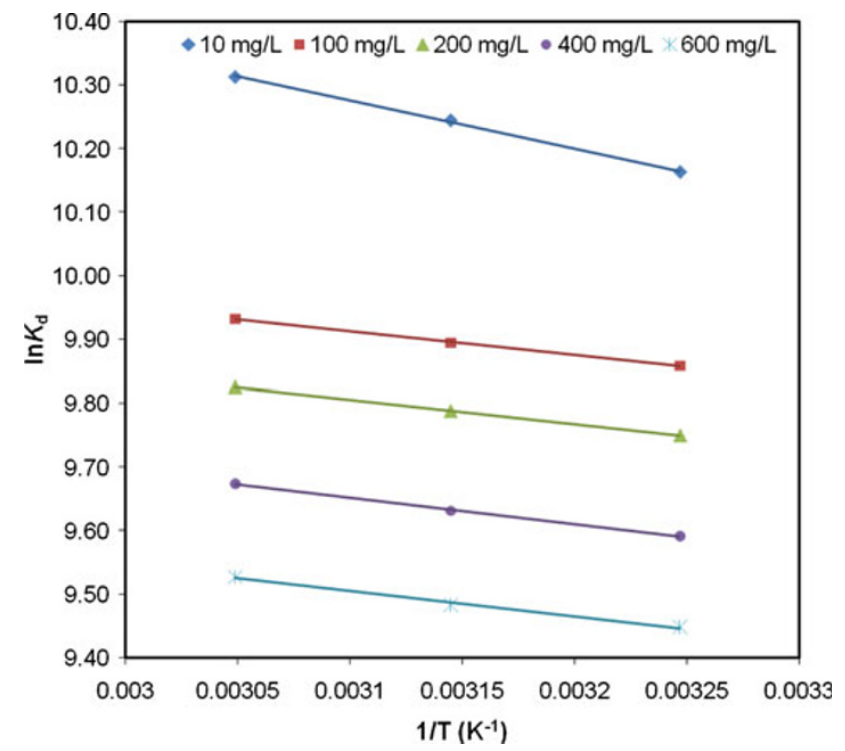

Fig. 8 Variation of $\ln K_{\mathrm{d}}$ with temperature (1/T) for the adsorption of EB onto SB (Van't Hoff plot) 
Table 2 Thermodynamic parameters for the adsorption of $\mathrm{EB}$ on $\mathrm{SB}$ at five different concentrations

\begin{tabular}{llllll}
\hline $\begin{array}{l}\text { Initial dye } \\
\text { concentration } \\
\left(\mathrm{mg} \mathrm{L}^{-1}\right)\end{array}$ & $\begin{array}{l}\Delta H^{\mathrm{o}} \\
\left(\mathrm{J} \mathrm{mol}^{-1}\right)\end{array}$ & $\begin{array}{l}\Delta S^{\mathrm{o}} \\
\left(\mathrm{J} \mathrm{mol}^{-1} \mathrm{~K}^{-1}\right)\end{array}$ & $308 \mathrm{~K}$ & $318 \mathrm{~K}$ & $328 \mathrm{~K}$ \\
\hline 10 & 91.09 & 1.52 & -376.43 & -391.61 & -406.79 \\
100 & 44.90 & 1.33 & -365.20 & -378.51 & -391.83 \\
200 & 46.25 & 1.32 & -360.89 & -374.11 & -387.32 \\
400 & 50.00 & 1.32 & -355.28 & -368.44 & -381.60 \\
600 & 47.81 & 1.29 & -349.69 & -362.60 & -375.50 \\
\hline
\end{tabular}

and spontaneous. Positive value of $\Delta H^{\mathrm{o}}$ confirms the endothermic nature the adsorption process. Hence, on increasing temperature, degree of adsorption will increase. The numerical value of $\Delta H^{\mathrm{o}}$ also predicts the physisorption behaviour of these adsorption processes. The positive values of $\Delta S^{\circ}$ reflect the affinity of SB towards EB and also indicate that the randomness is increased at the solid/ solution interface during the adsorption process (Acemioglu 2005; Yuan 2008; Ahmad et al. 2007; Bestani et al. 2008; Azhar et al. 2005).

\section{Adsorption isotherms parameters}

The adsorption isotherm studies provide information about the capacity of adsorbent to remove dyes under given set of conditions. Experimental results obtained for the adsorption of EB and MB dyes on agricultural waste SB at three different temperatures $(308,318$ and $328 \mathrm{~K})$ have been fitted to Langmuir isotherm model. The plot between $C_{\mathrm{e}} / q_{\mathrm{e}}$ and $C_{\mathrm{e}}$ yield straight lines (Fig. 9). The obtained $R^{2}$ values confirm that the adsorption equilibrium data fitted well to the Langmuir model under the studied conditions. These isotherms are found to be linear over the entire studied concentration range with extremely high $R^{2}$ values (Table 3$)$. The $R^{2}$ values suggest that the Langmuir isotherm provides a good model for the present adsorption systems. This indicates uniform adsorption and strong dyeadsorbent interactions over the surfaces of the adsorbent. Figs. 9a, b show the Langmuirian plots for EB and MB adsorption on SB, respectively. The values of the Langmuir constant $\left(K_{\mathrm{L}}\right)$, the monolayer capacity of adsorbent $\left(q_{\mathrm{m}}\right)$, and $R^{2}$ values are listed in Table 3 . The $q_{\mathrm{m}}$ values reveal that adsorption capacity of $\mathrm{SB}$ for $\mathrm{MB}$ adsorption $\left(1,000.0 \mathrm{mg} \mathrm{g}^{-1}\right)$ is double in comparison to EB adsorption $\left(500.0 \mathrm{mg} \mathrm{g}^{-1}\right)$. High $K_{\mathrm{L}}$ values also indicate the high affinity of SB for the adsorption of EB and MB.

The $R_{\mathrm{L}}$ parameter is considered as a more reliable indicator of adsorption. There are four possibilities for $R_{\mathrm{L}}$ values: (1) for favourable adsorption, $0<R_{\mathrm{L}}<1$; (2) for unfavourable adsorption, $R_{\mathrm{L}}>1$; (3) for linear adsorption, $R_{\mathrm{L}}=1$; and (iv) for irreversible adsorption, $R_{\mathrm{L}}=0$ (Senturk et al. 2009). In both the cases, the values of $R_{\mathrm{L}}$ (Table 3) are found to be positive and less than unity
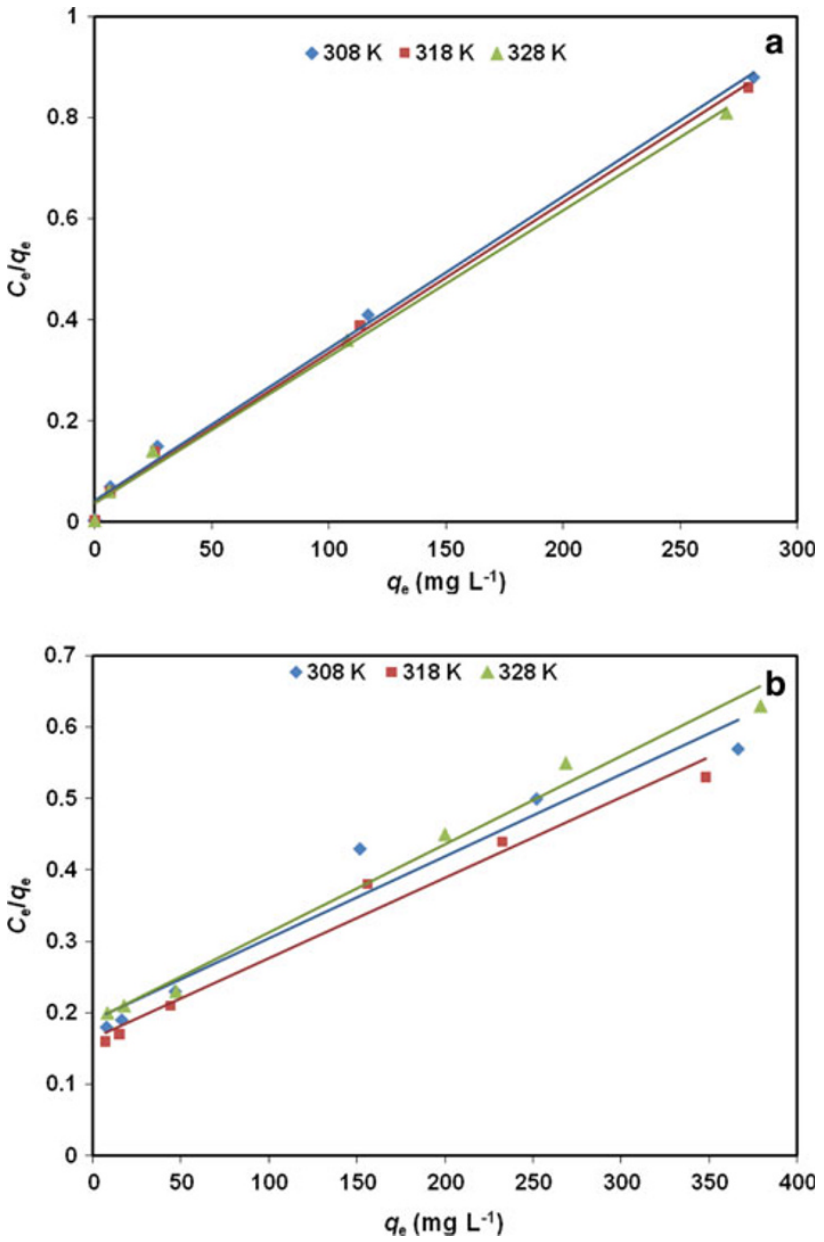

Fig. 9 Langmuir adsorption isotherms for; a EB adsorption on SB and $\mathbf{b}$ MB adsorption on SB at three different temperatures

indicating thereby a highly favourable adsorption in all cases.

Freundlich adsorption isotherm gives an expression encompassing the surface heterogeneity and the exponential distribution of active sites and their energies. For a favourable adsorption process, the value of $1 / n$ should be less than 1 and higher than 0.1 (Senturk et al. 2009). The Freundlich constants $K_{\mathrm{F}}$ and $1 / n$ are determined from the slope and intercept of $\ln q_{\mathrm{e}}$ versus $\ln C_{\mathrm{e}}$ plots (Fig. 10) and are tabulated in Table 3 along with the correlation 
Table 3 Adsorption isotherms constants for $\mathrm{EB}$ and $\mathrm{MB}$ adsorption on SB at three different temperatures

\begin{tabular}{|c|c|c|c|c|c|c|c|}
\hline \multirow[t]{2}{*}{ Isotherm } & \multirow[t]{2}{*}{ Parameters } & \multicolumn{3}{|c|}{ EB adsorption on SB } & \multicolumn{3}{|c|}{$\mathrm{MB}$ adsorption on $\mathrm{SB}$} \\
\hline & & $308 \mathrm{~K}$ & $318 \mathrm{~K}$ & $328 \mathrm{~K}$ & $308 \mathrm{~K}$ & $318 \mathrm{~K}$ & $328 \mathrm{~K}$ \\
\hline \multirow[t]{4}{*}{ Langmuir } & $q_{\mathrm{m}}\left(\mathrm{mg} \mathrm{g}^{-1}\right)$ & 333.3 & 333.3 & 500.0 & $1,000.0$ & $1,000.0$ & $1,000.0$ \\
\hline & $K_{L}\left(\mathrm{~L} \mathrm{mg}^{-1}\right)$ & 0.070 & 0.081 & 0.053 & 0.005 & 0.006 & 0.005 \\
\hline & $R^{2}$ & 0.99 & 0.99 & 0.99 & 0.95 & 0.98 & 0.99 \\
\hline & $R_{\mathrm{L}}$ & 0.023 & 0.020 & 0.031 & 0.159 & 0.140 & 0.158 \\
\hline \multirow[t]{3}{*}{ Freundlich } & $K_{F}$ & 2.16 & 2.80 & 3.33 & 0.11 & 1.17 & 1.05 \\
\hline & $1 / n$ & 0.42 & 0.39 & 0.38 & 0.68 & 0.68 & 0.67 \\
\hline & $R^{2}$ & 0.99 & 0.99 & 0.99 & 0.99 & 0.99 & 0.98 \\
\hline
\end{tabular}
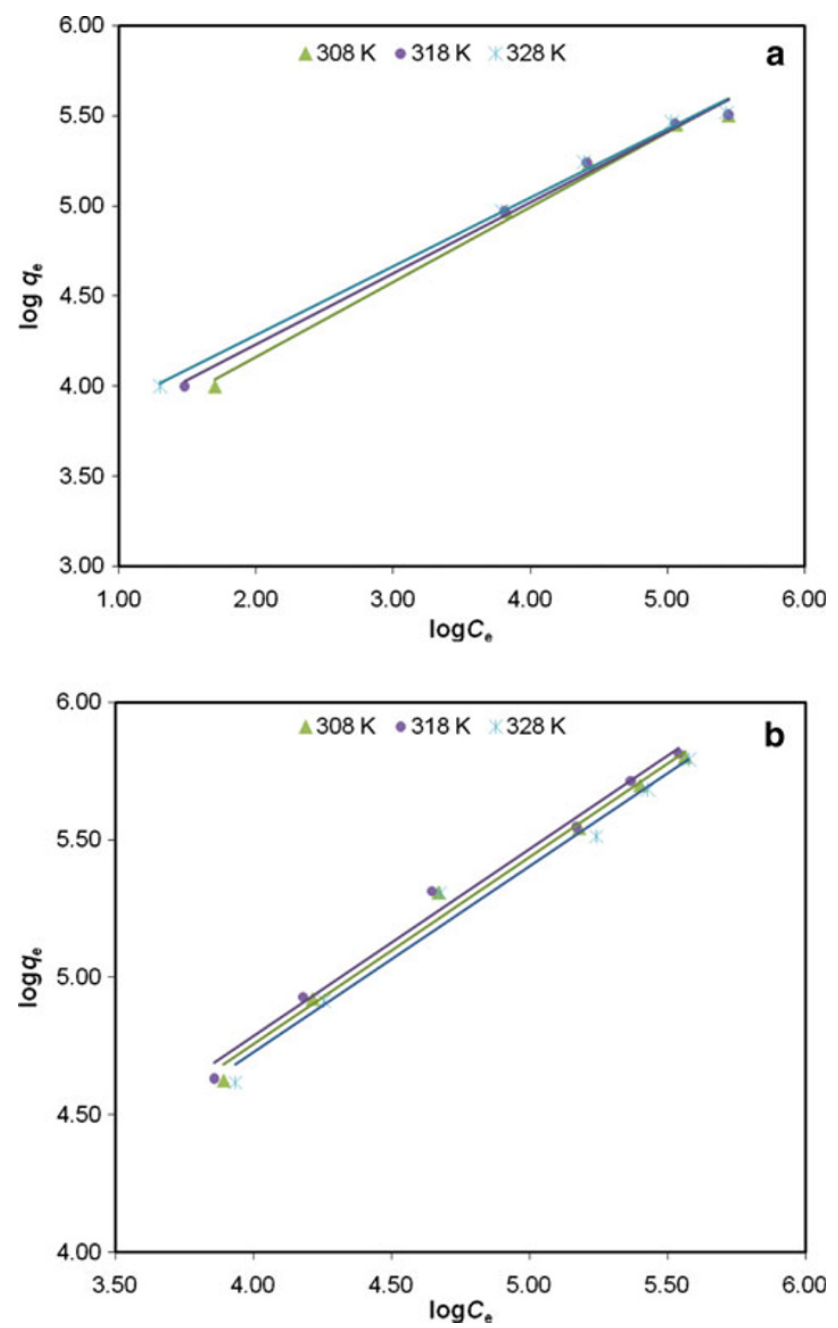

Fig. 10 Freundlich adsorption isotherms for; a EB adsorption on SB and $\mathbf{b} \mathrm{MB}$ adsorption on $\mathrm{SB}$ at three different temperatures

coefficient values $\left(R^{2}\right)$. The high correlation coefficients $\left(R^{2}=0.98-0.99\right)$ reflect that the experimental data agree well with the Freundlich adsorption isotherm model. The values of $1 / n$ are higher than 0.1 and smaller than 1 , indicating a favourable adsorption of dyes on SB.
According to the statistical theory of adsorption when the value of $1 / n$ is less than unity, it also implies heterogeneous surface with minimum interactions between the adsorbed molecules. The $K_{\mathrm{F}}$ values (Table 3 ) indicate that SB has good adsorption capacity for MB removal from aqueous system in comparison to EB. This isotherm does not predict any saturation of the adsorbent by the adsorbate thus infinite surface coverage is predicted mathematically indicating the multilayer sorption of the surface.

\section{Conclusions}

The removal of EB and MB from wastewater using SB has been investigated under different experimental conditions in batch mode. The adsorption of EB and MB has found to be dependent on the adsorbent dose and initial dye concentration. Thus, the efficient removal of these dyes from an effluent using SB may require $\mathrm{pH}$ adjustment 7-9. It has been found that optimum dose of $200 \mathrm{mg}$ of SB adsorbs 93.3\% EB and $83.6 \% \mathrm{MB}$ of initial dye concentration $\left(100 \mathrm{mg} \mathrm{L}^{-1}\right)$. Equilibration time of $1 \mathrm{~h}$ is sufficient between adsorbent and adsorbate to carry out the adsorption experiments for these adsorption systems and $308-318 \mathrm{~K}$ is the optimum temperature to perform the adsorption experiments and to achieve the maximum removal of dyes from aqueous waste. This work also presents the experimental results concerning monolayer and multilayer adsorption isotherms of dyes on SB. Both the adsorption isotherm models (Langmuir and Freundlich) give good agreement with experimental results for the adsorption of EB as well as $\mathrm{MB}$ on SB. A maximum monolayer adsorption capacity of SB is $500 \mathrm{mg} \mathrm{g}^{-1}$ for EB and $1,000 \mathrm{mg} \mathrm{g}^{-1}$ for MB. It is much higher than that of the other reported adsorbents (Sharma et al. 2010; Crini 2006; Gupta and Suhas 2009). The thermodynamics of EB-SB system indicates spontaneous and endothermic nature of the process. The obtained results reveal that the low-cost adsorbent (sugarcane bagasse) can be used for the removal of $\mathrm{EB}$ and $\mathrm{MB}$ from aqueous waste. 
Open Access This article is distributed under the terms of the Creative Commons Attribution License which permits any use, distribution and reproduction in any medium, provided the original author(s) and source are credited.

\section{References}

Acemioglu B (2005) Batch kinetic study of sorption of methylene blue by perlite. Chem Eng J 106:73-81

Ahmad AL, Loh MM, Aziz JA (2007) Preparation and characterization of activated carbon from oil palm wood and its evaluation on methylene blue adsorption. Dye Pigment 75:263-272

Aksu Z (2005) Application of biosorption for the removal of organic pollutants: a review. Process Biochem 40:997-1026

Ali I, Gupta VK (2007) Advances in water treatment by adsorption technology. Nat Protoc 1:2661-2667

Annadurai G, Juang RS, Lee DJ (2002) Use of cellulose-based wastes for adsorption of dyes from aqueous solutions. J Hazard Mater 92:263-274

Azhar SS, Liew AG, Suhardy D, Hafiz KF, Hatim MD (2005) Dye removal from aqueous solution by using adsorption on treated sugarcane baggase. Am J App Sci 2:1499-1503

Bestani B, Benderdouche N, Benstaali B, Belhakem M, Addou A (2008) Methylene blue and iodine adsorption onto an activated desert plant. Bioresour Technol 99:8441-8444

Bhattacharya KG, Sharma A (2004) Azadirachta indica leaf powder as an effective biosorbent for dyes: a case study with aqueous congo red solutions. J Environ Manag 71:217-229

Crini G (2006) Non-conventional low-cost adsorbents for dye removal: a review. Bioresour Technol 97:1061-1085

da Silva LG, Ruggiero R, Gontijo PDM, Pinto RB, Royer B, Lima EC, Fernandes THM, Calvete T (2011) Adsorption of Brilliant Red 2BE dye from water solutions by a chemically modified sugarcane bagasse lignin. Chem Eng J 168:620-628

El-Sayed GO (2011) Removal of methylene blue and crystal violet from aqueous solutions by palm kernel fiber. Desalination 272:225-232

Ferrero F (2007) Dye removal by low cost adsorbent: hazelnut shells in comparison with wood sawdust. J Hazard Mater 142:144-152

Freundlich HMF (1906) Uber die adsorption in Losungen. Z Phys Chem 57:385-470

Garg VK, Amita M, Kumar R, Gupta R (2004) Basic dye (methylene blue) removal from simulated wastewater by adsorption using Indian Rosewood sawdust: a timber industry waste. Dye Pigment 63:243-250

Gupta VK, Ali I (2008) Removal of endosulfan and methoxychlor from water on carbon slurry. Environ Sci Technol 42:766-770

Gupta VK, Suhas (2009) Application of low-cost adsorbents for dye removal—a review. J Environ Manag 90:2313-2342

Gupta VK, Mohan D, Sharma S, Sharma M (2000) Removal of basic dyes (rhodamine B and methylene blue) from aqueous solutions using bagasse fly ash. Sep Sci Technol 35:2097-2113

Gupta VK, Mittal A, Krishna L, Gajbe V (2004a) Adsorption kinetics and column operations for the removal and recovery of malachite green from wastewater using bottom ash. Sep Purif Technol 40:87-96

Gupta VK, Suhas AliI, Saini VK (2004b) Removal of rhodamine B, fast green, and methylene blue from wastewater using red mud, an aluminum industry waste. Ind Eng Chem Res 43:1740-1747

Gupta VK, Ali I, Saini VK, Van Gerven T, Van Bruggen BD, Vandecasteele C (2005) Removal of dyes from wastewater using bottom ash. Ind Eng Chem Res 44:3655-3664

Gupta VK, Mittal A, Gajbe V, Mittal J (2006a) Removal and recovery of the hazardous azo dye acid orange 7 through adsorption over waste materials: bottom ash and de-oiled soya. Ind Eng Chem Res 45:1446-1453

Gupta VK, Mittal A, Jain R, Mathur M, Sikarwar S (2006b) Adsorption of Safranin-T from wastewater using waste materialactivated carbon and activated rice husks. J Colloid Inter Sci 303:80-86

Gupta VK, Ali I, Saini VK (2007a) Adsorption studies on the removal of Vertigo Blue 49 and Orange DNA13 from aqueous solutions using carbon slurry developed from a waste material. J Colloid Inter Sci 315:87-93

Gupta VK, Jain R, Varshney S (2007b) Removal of Reactofix golden yellow 3 RFN from aqueous solution using wheat husk-an agricultural waste. J Hazard Mater 142:443-448

Gupta VK, Mittal A, Gajbe V, Mittal J (2008) Adsorption of basic fuchsin using waste materials - bottom ash and deoiled soya - as adsorbents. J Colloid Inter Sci 319:30-39

Gupta VK, Carrott PJM, Ribeiro Carrott MML, Suhas (2009a) Lowcost adsorbents: growing approach to wastewater treatment-a review. Crit Rev Environ Sci Technol 39:783-842

Gupta VK, Mittal A, Malviya A, Mittal J (2009b) Adsorption of carmoisine A from wastewater using waste materials-bottom ash and deoiled soya. J Colloid Inter Sci 335:24-33

Gupta VK, Gupta B, Rastogi A, Agarwal S, Nayak A (2011) A comparative investigation on adsorption performances of mesoporous activated carbon prepared from waste rubber tire and activated carbon for a hazardous azo dye-Acid Blue 113. J Hazard Mater 186:891-901

Hall KR, Eagleton LC, Acrivos A, Vermeulen T (1966) Pore and solid diffusion kinetics in fixed adsorption constant pattern conditions. Ind Eng Chem Res 5:212-223

Hameed BH (2009) Removal of cationic dye from aqueous solution using jackfruit peel as a non-conventional and low-cost adsorbent. J Hazard Mater 162:344-350

Han RP, Wang YF, Han P, Shi J, Yang J, Lu YS (2006) Removal of methylene blue from aqueous solution by chaff in batch mode. J Hazard Mater 137:550-557

Han R, Dandan D, Xu Y, Zou W, Wang Y, Li Y, Zou L (2008) Use of rice husk for the adsorption of Congo red from aqueous solution in column mode. Bioresour Technol 99:2938-2946

Jain AK, Gupta VK, Bhatnagar A, Suhas (2003) A comparative study of adsorbents prepared from industrial waste for the removal of dyes. Sep Sci Technol 38:463-481

Khattri SD, Singh MK (2011) Use of Sagaun sawdust as an adsorbent for the removal of crystal violet dye from simulated wastewater. Environ Prog Sustainable Energy. doi:10.1002/ep.10567

Kumar KV, Sivanesan S (2006) Equillibrium data isotherm parameters and process design for partial and complete isotherm of methylene blue onto activated carbon. J Hazard Mater 131:217-228

Lakshmi UR, Srivastva CV, Mall DI, Lataye DH (2009) Rice husk ash as an effective adsorbent: evaluation of adsorptive characteristics for indigo carmine dye. J Environ Manag 90: $710-720$

Langmuir I (1918) The adsorption of gases on plane surfaces of glass, mica and platinum. J Am Chem Soc 40:1361-1403

Low LW, Teng TT, Ahmad A, Morad N, Wong YS (2011) A novel pretreatment method of lignocellulosic material as adsorbent and kinetic study of dye waste adsorption. Water Air Soil Poll 218:293-306

Mall ID, Srivastva VC, Agarwal NK, Mishra IM (2005) Removal of Congo red from aqueous solution by baggase fly ash and activated carbon: kinetic study and equilibrium isotherm analyses. Chemosphere 61:492-501

Mohanty K, Naidu JT, Meikap BC, Biswas MN (2006) Removal of crystal violet from wastewater by activated carbons prepared from rice husk. Ind Eng Chem Res 45:5165-5171 
Saad SA, Isa KM, Bahari R (2010) Chemically modified sugarcane bagasse as a potentially low-cost biosorbent for dye removal. Desalination 264:123-128

Saha P (2010) Assessment on the removal of methylene blue dye using tamarind fruit shell as biosorbent. Water Air Soil Poll 217:287-299

Senturk HB, Ozdes D, Gundogdu A, Duran C, Soylak M (2009) Removal of phenol from aqueous solutions by adsorption onto organomodified Tirebolu bentonite: equilibrium, kinetic and thermodynamic study. J Hazard Mater 172:353-362

Sharma P, Tomar R (2011) Sorption behaviour of nanocrystalline MOR type zeolite for Th(IV) and Eu(III) removal from aqueous waste by batch treatment. J Colloid Inter Sci 362:144-156

Sharma P, Kaur R, Baskar C, Chung WJ (2010) Removal of methylene blue from aqueous waste using rice husk and rice husk ash. Desalination 259:249-257

Sharma P, Kaur H, Sharma M, Sahore V (2011) A review on applicability of naturally available adsorbents for the removal of hazardous dyes from aqueous waste. Environ Monit Assess. doi: 10.1007/s10661-011-1914-0

Sivaraj R, Namasivayam C, Kadirvelu K (2001) Orange peel as an adsorbent in the removal of Acid violet 17 from aqueous solutions. Waste Manag 21:105-110

Weber TW, Chakravorti RK (1974) Pore, solid diffusion models for fixed bed adsorbers. AIChE J 20:228-238

Yuan Z (2008) Kinetics and Mechanism of the adsorption of methylene blue onto ACFs. J China Univ Min Technol 18:0437-0440

Zahrim AY, Tizaoui C, Hilal N (2011) Coagulation with polymers for nanofiltration pre-treatment of highly concentrated dyes: a review. Desalination 266:1-16

Zhang G, Li X, Li Y, Wu T, Sun D, Lu F (2011) Removal of anionic dyes from aqueous solution by leaching solutions of white mud. Desalination 274:255-261 